\title{
Variabilidade diária da zonação da macrofauna bentônica em praias arenosas do litoral norte do Rio Grande do Sul
}

\author{
Frederico Monteiro Neves ${ }^{1} \&$ Carlos Emílio Bemvenuti ${ }^{2}$
}

\begin{abstract}
1. Doutorado em Meio Ambiente e Desenvolvimento, Universidade Federal do Paraná, Rua dos Funcionários, 1540, $80035-050$ Curitiba, PR, Brasil. (fmonteironeves@yahoo.com.br)

2. Departamento de Oceanografia, Fundação Universidade Federal do Rio Grande, Caixa Postal 474, 96201-900 Rio Grande, RS, Brasil (docbemve@furg.br)
\end{abstract}

\begin{abstract}
Daily zonation variation of sandy beach benthic macrofauna in north coast of the Rio Grande do Sul, Brazil. This work verified the daily zonation of benthic macrofauna in Tramandaí, Harmonia and Jardim do Éden beaches, north coast of the state of Rio Grande do Sul, southern Brazil, for five consecutive days. Biological data were collected with a PVC core $(20 \mathrm{~cm}$ diameter $)$ along three transects distant $50 \mathrm{~m}$ of each other, with four levels and three samples in each level. First level was always positioned $8 \mathrm{~m}$ above the superior limit of swash zone and the last one was $1 \mathrm{~m}$ depth. There was also daily data collection of beach topographical profiles. Benthic macrofauna organisms showed a regular pattern of zonation along all days, with intertidal zone marked by the presence of the isopod Excirolana armata (Dana, 1853) and the polychaeta Euzonus furciferus (Ehlers, 1897). Swash zone was represented by a high abundance of the hippid crab Emerita brasiliensis (Schmitt, 1935), the pelecypod Donax hanleyanus (Philippi, 1842) and the polychaeta Scolelepsis gaucha (Orensanz \& Gianuca, 1974). Surf zone and breaker zone did not show differences in species composition, being dominated by juvenile D. hanleyanus, Mesodesma mactroides (Deshayes, 1854), the amphipode Phoxocephalopsis zimmeri (Schellenberg, 1931), the polychaeta Hemipodus olivieri (Orensanz \& Gianuca, 1974) and the bivalve Donax gemmula (Morrison, 1971). Results indicated that benthic macrofauna zonation pattern was regular, although some changes in vertical species position along the transect was observed, mainly due to swash zone variation.
\end{abstract}

KEYWORDS. Benthic macrofauna, sandy beaches, zonation, Rio Grande do Sul.

RESUMO. O objetivo deste trabalho é verificar a variação diária da zonação da macrofauna bentônica nas praias de Tramandaí, Harmonia e Jardim do Éden, Rio Grande do Sul. As coletas foram feitas ao longo de cinco dias consecutivos, utilizando-se um tubo de PVC de $20 \mathrm{~cm}$ de diâmetro. Foram demarcadas três transversais distantes $50 \mathrm{~m}$ uma da outra, com 4 estações de coleta e três amostras cada. As estações se estenderam desde $8 \mathrm{~m}$ acima do limite superior da zona de varrido (definida a cada dia) até $1 \mathrm{~m}$ de profundidade. Também foram coletados diariamente dados dos perfis topográficos de cada praia. Os resultados mostraram que a macrofauna bentônica apresenta um padrão de zonação regular ao longo dos dias. O intermareal foi marcado pela presença do isópode Excirolana armata (Dana, 1853) e do poliqueta Euzonus furciferus (Ehlers, 1897). A zona de varrido apresentou grande abundância do caranguejo hipídeo Emerita brasiliensis (Schmitt, 1935), do bivalvo Donax hanleyanus (Philippi, 1842) e do poliqueto Scolelepis gaucha (Orensanz \& Gianuca, 1974). As zonas de "surf" e arrebentação interna não apresentaram diferenças na composição de espécies, sendo dominantes os juvenis de D. hanleyanus, Mesodesma mactroides (Deshayes, 1854), o anfípode Phoxocephalopsis zimmeri (Schellenberg, 1931), o poliqueto Hemipodus olivieri (Orensanz \& Gianuca, 1974), além do bivalve Donax gemmula (Morrison, 1971). Os resultados indicaram que, apesar do padrão de zonação da macrofauna ter sido regular ao longo do estudo, algumas mudanças na posição vertical das espécies foram observadas, principalmente em função da variação da zona de varrido.

PALAVRAS-CHAVE. Macrofauna bentônica, praias arenosas, zonação, Rio Grande do Sul.

A variação na distribuição, composição e estrutura das comunidades bentônicas de praias arenosas tem sido relacionada a mudanças em parâmetros ambientais, como precipitação, temperatura (LEBER, 1982) e morfodinâmicos (McLachlan, 1990, 1996; McLachlan et al., 1993; JARAMillo et al., 1993; MCLAChLAN \& JARAMillo, 1995). A geomorfologia das praias arenosas resulta da ação de fatores como vento, ondas e marés, que associados determinam a granulometria do sedimento (BRown \& MCLACHLAN, 1990). Geralmente, quanto maior o tamanho do grão de sedimento, mais íngreme o perfil da praia (VILLWOCK, 1994), sendo a diversidade e abundância biológicas inversamente proporcionais ao tamanho do grão de sedimento (McLACHLAN, 1983).

A macrofauna bentônica de praias arenosas pode apresentar um padrão de zonação, distribuição em manchas e flutuações devido à hidrodinâmica praial e fatores biológicos, tais como, recrutamentos e migrações. As manchas resultam, principalmente, da seleção passiva pelas ondas e da concentração de alimento localizada, sendo que a escala das manchas pode variar de $10 \mathrm{~m}$, em praias reflectivas (McLaCHLAN \& Hesp, 1984) até 100 m, em praias dissipativas de alta energia (TARR et al., 1985).

MCLACHLAN \& JARAMILlo (1995) consideraram que não existe relação entre as zonas faunísticas da praia e os níveis de maré médios ou de longo-prazo. Eles concluem que as zonas se ajustam cada dia aos limites da praia, definidos pela variação da zona de varrido, e distinguem três zonas faunísticas: o supralitoral, o litoral e o sublitoral. RAFFAELLI et al. (1991) consideraram que, excetuando as zonas mais altas da praia, torna-se difícil definir as zonas biológicas em praias arenosas.

Não existem trabalhos sobre a variabilidade temporal diária do macrozoobentos em praias arenosas do sul do Brasil. A maioria dos estudos aborda a distribuição, dinâmica populacional e produção secundária de espécies da fauna bentônica de praias arenosas (Gianuca, 1983; Borzone \& Gianuca, 1990; 
Souza \& GianuCa, 1995; Borzone et al., 1996; Borzone \& SouZA, 1997).

Além da necessidade de investigar a distribuição espacial e temporal da macrofauna bentônica em praias do litoral norte do Rio Grande do Sul, também há a urgência de se conhecer melhor estes ambientes em função do crescente impacto antrópico a que estão submetidos. Neste sentido, observa-se que a praia de Tramandaí, litoral norte do Rio Grande do Sul, além de receber um intenso aporte de turistas nos meses de verão, encontra-se ainda numa região em que ocorre o descarregamento, transporte e armazenamento de petróleo bruto, nafta e diesel, sendo a região considerada como um ambiente vulnerável a derrames de petróleo (Schwarzbold \& Wurdig, 1992).

Neste sentido, objetiva-se identificar os padrões de distribuição vertical de curto prazo da macrofauna bentônica de três praias do litoral norte do Rio Grande do Sul, dando ênfase à variação diária, e compreender como as diversas espécies se posicionam na praia (perante variações ambientais diárias).

\section{MATERIAL E MÉTODOS}

A amostragem da macrofauna bentônica foi realizada diariamente entre os dias 7 e 11 de abril de 2003 ao lado da plataforma de pesca da praia de Tramandaí $\left(30^{\circ} 00^{\prime} \mathrm{S}\right.$ e $\left.50^{\circ} 07^{\prime} \mathrm{W}\right)$, a $10 \mathrm{~km}$ ao norte na praia de Harmonia $\left(29^{\circ} 54^{\prime} \mathrm{S}\right.$ e $\left.50^{\circ} 05^{\prime} \mathrm{W}\right)$ e a $10 \mathrm{~km}$ ao sul da estação de coleta de Tramandaí, na praia de Jardim do Éden $\left(30^{\circ} 05^{\prime} \mathrm{S}\right.$ e $50^{\circ} 10^{\prime} \mathrm{W}$ ) (Fig. 1).

Perfis topográficos foram traçados diariamente na mesma linha da amostragem biológica, para registrar a forma da praia no momento das coletas. Para tal, utilizouse um nível topográfico, régua graduada e bússola de geólogo de acordo com o método proposto por BIRKEMEIER (1985). Os pontos seguiram as feições geomorfológicas da praia desde a base da duna frontal até a zona de arrebentação interna.

O estado morfodinâmico das praias foi descrito pelo parâmetro W [W = $\left.\mathrm{H}_{\mathrm{b}} /\left(\mathrm{T} \mathrm{x} \mathrm{W}_{\mathrm{s}}\right)\right]$ de Dean, de acordo com WRIGHT \& SHORT (1984). Foram diariamente registrados: a velocidade do vento (anemômetro), o período e a altura das ondas (observações visuais), a temperatura da água e do ar (termômetro) e a salinidade (refratômetro).

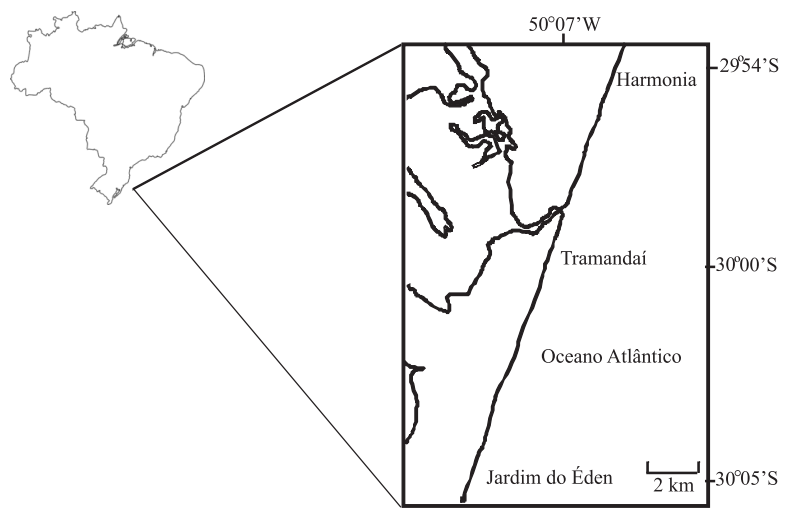

Fig. 1. Localização da área de estudo. As praias de Jardim do Éden e Harmonia estão localizadas a $10 \mathrm{~km}$ da praia de Tramandaí.
Para a coleta da macrofauna foram demarcadas três transversais, em cada uma das três praias, que se estenderam desde as dunas primárias, passando pelos níveis supralitoral, mesolitoral, zona de varrido (ainda no mesolitoral), até cerca de $1 \mathrm{~m}$ de profundidade na zona de arrebentação interna. As transversais localizaram-se a 50 m uma da outra em cada praia (Fig. 2).

As coletas iniciaram diariamente às $8 \mathrm{~h}$ e se encerravam aproximadamente às $15 \mathrm{~h}$. Como foi inviável realizar a amostragem simultânea nas três praias, a cada dia a amostragem era realizada numa sequiência diferente nas três praias para minimizar qualquer efeito do horário de coleta nos resultados.

A partir do nível superior do mesolitoral até $1 \mathrm{~m}$ de profundidade foram estabelecidas quatro estações de coleta, nas quais foram efetuadas amostragens quantitativas de macrozoobentos. A estação 1 foi posicionada $8 \mathrm{~m}$ acima do limite superior da zona de varrido a partir de medidas efetuadas diariamente no momento da coleta. A estação 2 esteve sempre localizada na zona de varrido. A estação 3 ficou situada no limite entre a zona de varrido e o início da zona de arrebentação interna, enquanto a estação 4 ficou posicionada na zona de arrebentação interna, a cerca de $1 \mathrm{~m}$ de profundidade.

Foi medida a distância (trena métrica) entre as estações extremas ( 1 e 4), sendo esta subdividida para determinar a posição equidistante das estações intermediárias (2 e 3). Em cada estação foram coletadas três amostras por transversal, totalizando 36 amostras por dia em cada praia. Durante os cinco dias de estudo foram coletadas 540 amostras da macrofauna com tubo de PVC. A distância entre as estações e as dunas foi registrada diariamente para a verificação da variação dos limites da zona de varrido.

As amostras foram tomadas utilizando-se um tubo extrator de PVC com $20 \mathrm{~cm}$ de diâmetro $\left(0,031 \mathrm{~m}^{2}\right)$ enterrado a $20 \mathrm{~cm}$ de profundidade. As amostras biológicas foram peneiradas ainda no campo com uma malha de nylon de $0,5 \mathrm{~mm}$ de abertura de poro e fixadas em formalina a $10 \%$. Os organismos foram identificados até o menor táxon possível com o auxílio de microscópios estereoscópicos, e quantificados. A densidade foi extrapolada para indivíduos por metro quadrado.

A presença de grandes concentrações da diatomácea Asterionellopsis glacialis (Fragilariaceae) na

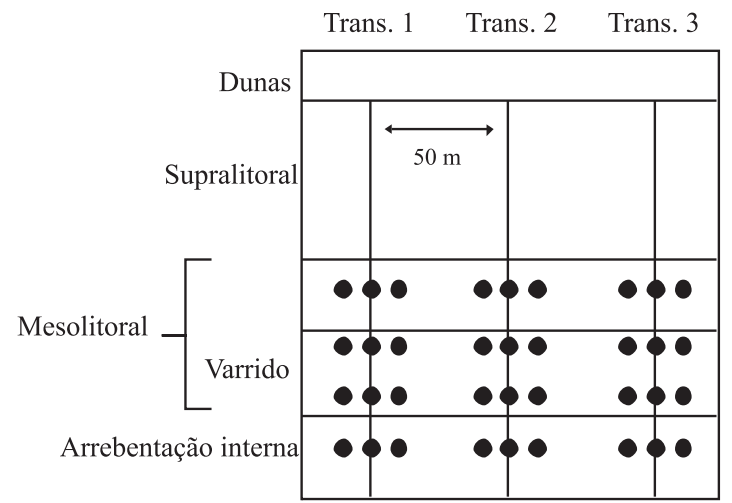

Fig. 2. Desenho amostral das coletas quantitativas da macroinfauna (Trans., transversal; $\bullet$, amostra). 
zona de arrebentação e varrido foi monitorada diariamente através da visualização de manchas amarronzadas. Além disto, como era notória na zona de varrido a presença de indivíduos adultos do equinóide Mellita quinquiesperforata (Leske, 1778) e do gastrópode Olivancillaria auricularia (Lamarck, 1810), estes foram quantificados visualmente.

No penúltimo dia de amostragem, 36 amostras de sedimento foram coletadas em cada estação em todas as praias utilizando-se um tubo de PVC de $20 \mathrm{~cm}$ de diâmetro. Estas amostras foram analisadas no Laboratório de Oceanografia Geológica da Fundação Universidade Federal do Rio Grande (FURG).

A partir da planilha original de densidade (ind/0,031 $\mathrm{m}^{2}$ ) das espécies por amostra, foram realizadas as análises estatísticas no programa PRIMER v5 (Plymouth Routines in Multi Ecological Research). Primeiramente, foi extraída para cada praia, uma planilha de similaridade entre amostras pareadas (modo Q) com transformação de raiz quadrada através do índice de Bray-Curtis (RAFFAELLI et al., 1991).

O passo seguinte foi testar, através da análise de similaridade (ANOSIM-one way), a hipótese de que não havia diferenças entre transversais dentro de cada praia. As análises de similaridade foram realizadas com os dados gerais de cada praia, a seguir com os dados de cada dia dentro de cada praia e finalmente com os dados das três praias (utilizando as estações como fatores) para verificar a existência de um padrão de distribuição da fauna. Para os dados das três praias em conjunto trabalhou-se com a média das amostras de cada estação ( 3 amostras) dentro de cada transversal para cada praia, separadamente. Foram considerados grupos diferentes aqueles com nível de significância $\mathrm{p}<0,05$ e $\mathrm{R}>0,5$. Os valores de $\mathrm{R}$ variam de -1 a 1 , sendo que valores próximos a 1 indicam grupos totalmente diferentes e valores próximos a zero indicam grupos similares.

A partir da planilha de similaridade foi feita uma análise de ordenação MDS (Non-metric Multi-dimension Scaling) para cada praia, para cada dia dentro de cada praia e para os dados das três praias juntas. Esta análise permite a visualização em duas dimensões da ordenação das amostras de acordo com o grau de similaridade entre estas. Para verificar a contribuição de cada espécie nas diferenças entre dois grupos foi feita uma análise de porcentagem de similaridade (SIMPER). Esta análise indica quais espécies são responsáveis pelo padrão de agrupamento observado e pelas diferenças entre grupos de amostras que foram definidos a priori.

\section{RESULTADOS}

Dados Ambientais. Este trabalho foi realizado entre dois fenômenos de ressaca. Um dia antes do início da amostragem, a velocidade média do vento em Tramandaí foi de $9 \mathrm{~m} / \mathrm{s} \mathrm{SW}$, com altura de onda de $3 \mathrm{~m}$ e $14 \mathrm{~s}$ de período. Nas três praias estudadas, o primeiro dia amostral foi marcado por velocidades do vento na casa de $4 \mathrm{~m} / \mathrm{s}$ SW (Fig. 3) e o último dia alcançou médias de 9,5 m/s W. O período de onda foi de $14 \mathrm{~s}$ no primeiro dia (Fig. 4), chegando a $9 \mathrm{~s}$ no último dia. A altura de onda variou de $2,5 \mathrm{~m}$ (Fig. 5) no primeiro dia, chegou a 1,5 $\mathrm{m}$ no quarto dia e a $1,75 \mathrm{~m}$ no último dia. A temperatura da água variou de $19^{\circ} \mathrm{C}$ a $23^{\circ} \mathrm{C}$ e a salinidade de 32 a 34 .

As praias de Tramandaí, Harmonia e Jardim do Éden apresentaram estágio praial do tipo dissipativo nos cinco dias de estudo $(6,7<\mathrm{W}<8,9 / 5,7<\mathrm{W}<10,1 / 6,7<\mathrm{W}<$ 8,9 , respectivamente), exceto no quarto dia, na praia de Harmonia, quando esta apresentou estágio semelhante a "banco e praia rítmica" ( $\mathrm{W}=4,3)$. A declividade média das praias foi de $1,3^{\circ}$, para Tramandaí, e $2^{\circ}$ para Harmonia e Jardim do Éden. O sedimento foi classificado como areia fina em todas as estações dentro das três praias, e apresentou tamanho médio de grão variando de $0,19 \mathrm{~mm}$ a $0,25 \mathrm{~mm}$.

Durante o período estudado, na praia de Tramandaí ocorreu uma pequena variação da distância das dunas até o limite superior da zona de varrido. Já nas praias de

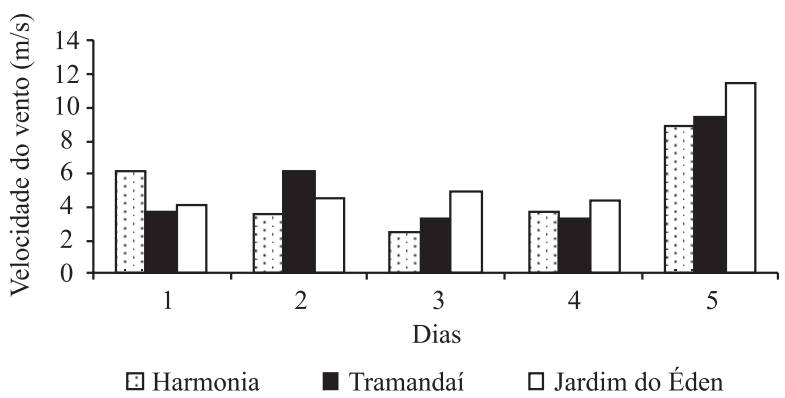

Fig. 3. Velocidade do vento nas três praias durante os cinco dias de estudo (abril de 2003).

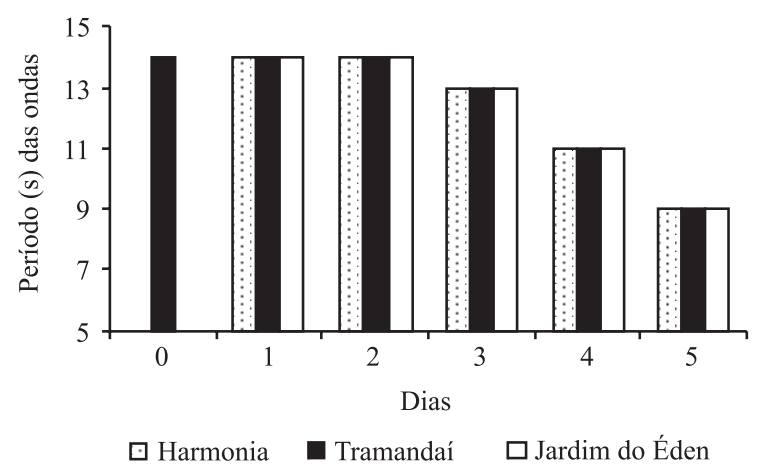

Fig. 4. Período das ondas nas três praias estudadas ao longo dos cinco dias de amostragem (abril de 2003). O dia zero corresponde a medição no dia anterior ao início da coleta de dados, onde verificou-se o período de onda somente na praia de Tramandaí.

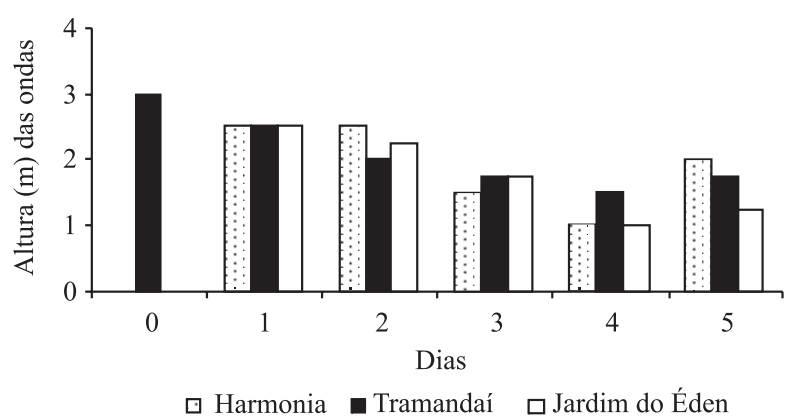

Fig. 5. Altura das ondas nas três praias estudadas ao longo dos cinco dias de amostragem (abril de 2003). O dia zero corresponde a medição no dia anterior ao início da coleta de dados, onde verificouse a altura das ondas somente na praia de Tramandaí. 
Harmonia e Jardim do Éden, foi notória uma variação pronunciada nesta distância (Fig. 6).

$\mathrm{Na}$ zona de arrebentação e varrido foi verificada (observação visual) a presença da diatomácea Asterionellopsis glacialis. Esta espécie esteve presente nos dias 1,2 e 5 (em menor quantidade) nas praias de Tramandaí e Harmonia, ao passo que na praia de Jardim do Éden, estas manchas foram encontradas somente nos dois primeiros dias.

Praia de Tramandaí. Através de observação visual foi verificado que o equinóide Mellita quinquiesperforata ocorreu na zona de varrido nos dias 1 e 3 , em número de 8 e 4 indivíduos, respectivamente. O gastrópode Olivancillaria auricularia foi encontrado em número de $8,3,1,3$ e mais de 10 indivíduos ao longo dos cinco dias, respectivamente.

A estrutura da macrofauna bentônica da praia de Tramandaí apresentou variação diária. Nos dias 1 e 3 , apenas dois grupos foram distintos (Fig. 7), os quais foram formados pela estação 1 e as estações 2,3 e 4 . O isópode Excirolana armata (Dana, 1853) dominou a estação $1 \mathrm{em}$ ambos os dias (contribuição > 90\%). No dia 1, o segundo grupo foi dominado pelo bivalve Donax hanleyanus (Philippi, 1842), o hipídeo Emerita brasiliensis (Schmitt, 1935) (37\% - estação 2), o bivalve Mesodesma mactroides (Deshayes, 1854) e o anfípode Puelche orensanzi (Barnard \& Clark, 1982) (77\% - estação 4). Por outro lado, no dia 3, neste grupo predominaram $M$. mactroides (contribuição > 45\%) e P. orensanzi (40\%).

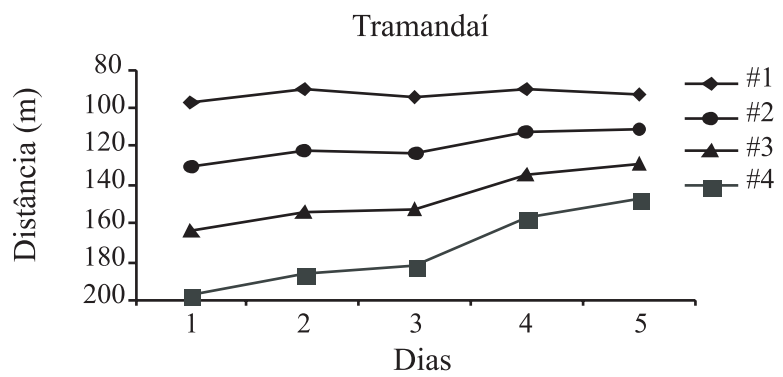

Harmonia
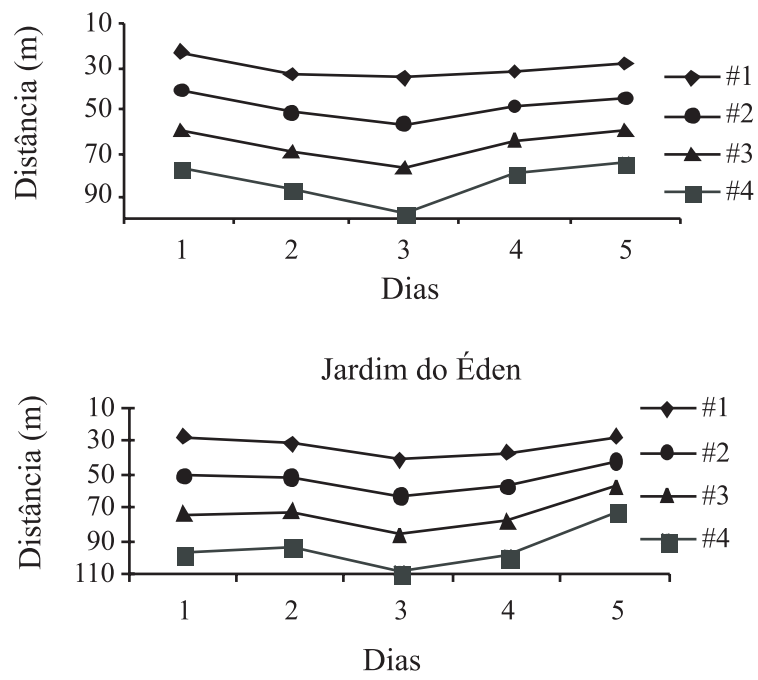

Fig. 6. Variação da distância das estações de coleta (\#1, \#2, \#3, \#4) em relação às dunas nas três praias estudadas, ao longo dos cinco dias de amostragem (abril de 2003).
No segundo dia, apenas as estações 1 e 2 (Fig. 7) e 1 e 3 apresentaram diferenças. Cerca de $70 \%$ da diferença entre as estações 1 e 2 foi devida à presença de Excirolana armata e D. hanleyanus na estação 1 e de Emerita brasiliensis somente na estação 2. A estação 3 se diferenciou da 1 pela presença de M. mactroides (30\% de contribuição nas diferenças) na estação 3 , além das espécies supracitadas para a estação 1 .

No dia 4, ocorreu a separação de 3 estações: a estação 1, representada pelas espécies E. armata e o poliqueta Euzonus furciferus (Ehlers, 1897), as quais contribuíram juntas com cerca de $99 \%$ da similaridade desta estação; a estação 2, composta principalmente por E. brasiliensis e D. hanleyanus $(96 \%$ de similaridade interna); e, por último, a estação 4, representada pelo bivalve Donax gemmula (Morrison, 1971) (44\% de contribuição) e $P$. orensanzi ( $26 \%$ de contribuição). A estação 3 apresentou espécies similares às outras três estações (Fig. 7).

No último dia, mais uma vez o padrão foi representado por três estações distintas: a estação $1(E$. armata), a estação 2 (D. hanleyanus, $E$. furciferus e $E$. brasiliensis) e a estação 4, composta principalmente por D. hanleyanus, D. gemmula e os anfípodes Phoxocephalopsis sp. e P. orensanzi (Fig. 7).

Algumas espécies menos abundantes (Tab. I), como os poliquetas Hemipodus olivieri (Orensanz \& Gianuca, 1974) e Sigalion cirriferum (Orensanz \& Gianuca, 1974), foram encontradas nos 4 primeiros dias nas estações 3 e 4 . Hemipodus olivieri também ocorreu na estação 2 nos dias 3 e 4 .

A variação na posição vertical da macrofauna bentônica na praia de Tramandaí foi menor que nas praias de Harmonia e Jardim do Éden.

Praia de Harmonia. Através da observação visual, foi verificado que Mellita quinquiesperforata e $O$. auricularia ocorreram na zona de varrido com mais de 10 indivíduos cada, exceto no último dia, quando não houve registro destes. Também no penúltimo dia não houve registro de $M$. quinquiesperforata.

A estrutura da macrofauna bentônica mostrou no dia 1 a separação de 3 grupos: estação 1, estação 2 e estações 3 e 4 . A estação 1 foi marcada pela presença de E. armata $($ similaridade média $=61 \%$ ); a estação 2 caracterizou-se pela maior densidade de E. brasiliensis (similaridade média $=40 \%$ ) e as estações 3 e 4 pela presença de juvenis de $D$. hanleyanus e, em menor grau, pelos poliquetas Scolelepis gaucha (Orensanz \& Gianuca, 1974) e Hemipodus olivieri (Fig. 7).

O dia 2 apresentou o mesmo padrão do primeiro dia, com 3 grupos (Fig. 7). Na estação 1 houve o domínio de $E$. armata (Similaridade média $=59 \%$ ); a estação 2 apresentou alta densidade do poliqueta $S$. gaucha $(1770$ ind $/ \mathrm{m}^{2}$ ) e de E. brasiliensis. As estações 3 e 4 foram dominadas por juvenis de $M$. mactroides e $D$. hanleyanus.

No dia 3, somente a estação 1 diferiu das demais (Fig. 7). Esta estação se caracterizou, mais uma vez, pela alta densidade de $E$. armata e presença de $E$. furciferus. As estações 2, 3 e 4 apresentaram altas densidades de $M$. mactroides, D. gemmula, D. hanleyanus, $P$. orensanzi e E. brasiliensis. 
O dia 4 seguiu o mesmo padrão do dia anterior, com somente dois grupos faunísticos distintos: um caracterizado pela dominância de E. armata e E. furciferus e o outro formado pelas estações 2, 3 e 4, caracterizado pela presença de $M$. mactroides, S. gaucha, D. hanleyanus e em menor abundância, P. orensanzi, E. brasiliensis e D. gemmula (Fig. 7).

$\mathrm{O}$ último dia apresentou características distintas dos demais (Fig. 7), pois a estação 3 foi semelhante a todas às outras. A estação 1 foi diferente das estações 2
( $R>0,7)$ e 4 ( $R>0,7)$, e a estação 2 diferiu da estação 4 ( $R$ $=0,7 ; \mathrm{p}=0,01)$. Mais uma vez, E. armata dominou a estação 1, juntamente com o poliqueta E. furciferus (Tab. II). A estação 2 apresentou maiores densidades de $D$. hanleyanus, E. brasiliensis e E. furciferus e a estação 4 foi dominada por $D$. hanleyanus e $M$. mactroides.

As espécies Phoxocephalopsis sp. e P. orensanzi foram organismos característicos dos níveis mais baixos da praia (estações 3 e 4), apesar de terem sido pouco abundantes (Tab. II).

\section{Tramandaí \\ Harmonia \\ Jardim do Éden}

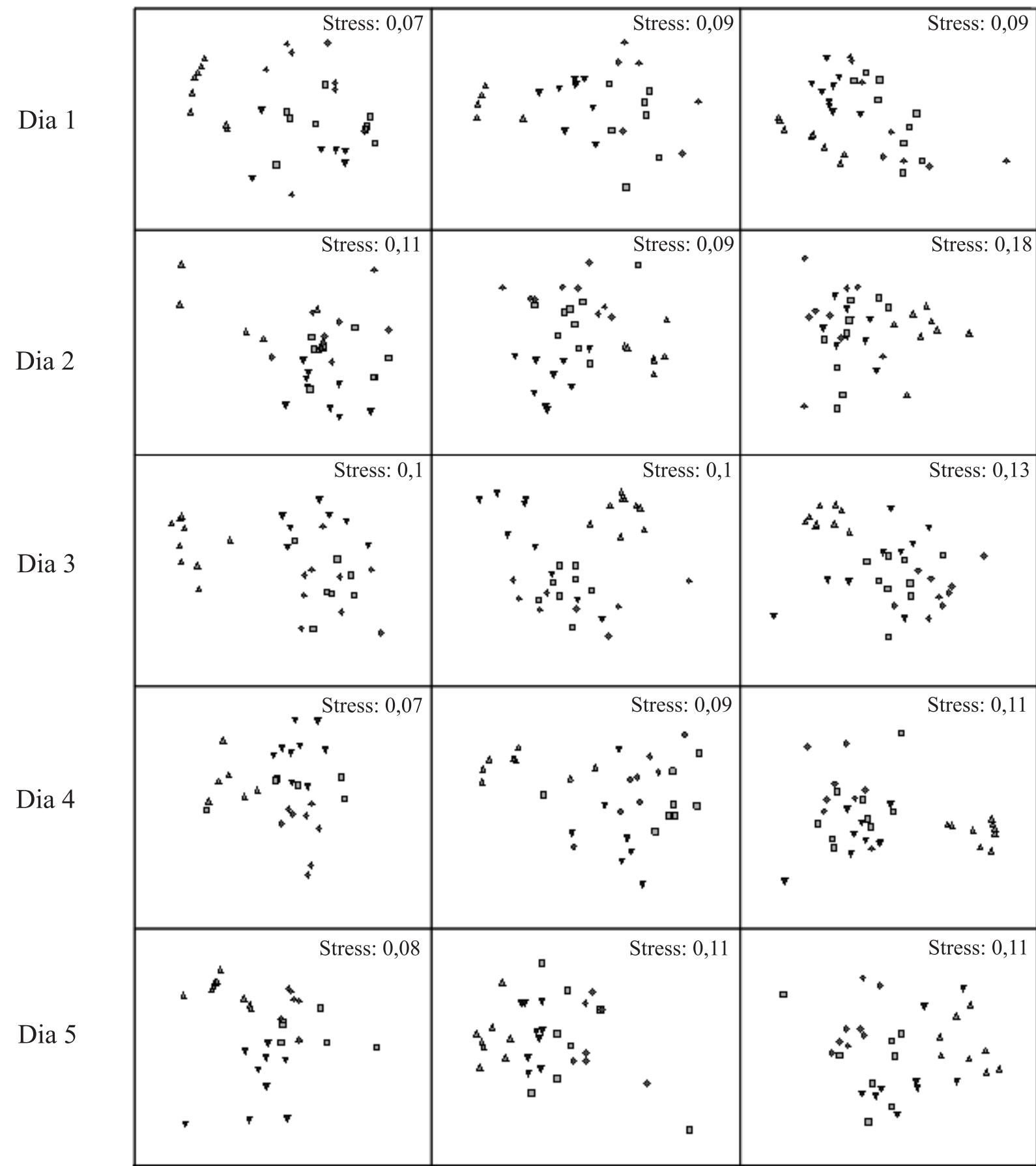

Fig. 7. Análise de ordenação MDS da distribuição vertical das amostras das três praias estudadas ao longo dos cinco dias de amostragem (abril de 2003) ( $\boldsymbol{\Delta}$, estação $1 ; \boldsymbol{\nabla}$, estação $2 ; \boldsymbol{\nabla}$, estação $3 ; \boldsymbol{\square}$, estação 4 ). 
Praia de Jardim do Éden. Na zona de varrido verificou-se (quantificação visual) a presença de dezenas de equinóides $M$. quinquiesperforata nos dias 1,2 e 3 e do gastrópode $O$. auricularia, em menor número (4 indivíduos) nos dias 2,3 e 4.

A estrutura diária do macrozoobentos mostrou no primeiro dia a formação de 3 grupos (Fig. 7). Um grupo formado pela estação 1 , outro pela estação 2 e o terceiro pelas estações 3 e 4 . A estação 1 foi dominada por $E$. armata (91\% de contribuição na similaridade interna). As estações 2 e 3 foram diferentes cerca de $70 \%$ devido às presenças de $D$. hanleyanus e $S$. gaucha em maior abundância na estação 2 , enquanto $M$. mactroides foi mais abundante na estação 3 . As estações 3 e 4 foram

Tabela I. Densidade média diária (ind. $/ \mathrm{m}^{2}$ ) das espécies da praia de Tramandaí por estação amostral.

\begin{tabular}{|c|c|c|c|c|c|c|c|c|c|c|c|c|c|c|c|c|c|c|c|c|}
\hline & \multicolumn{4}{|c|}{07.04 .2003} & \multicolumn{4}{|c|}{08.04 .2003} & \multicolumn{4}{|c|}{09.04 .2003} & \multicolumn{4}{|c|}{10.04 .2003} & \multicolumn{4}{|c|}{11.04 .2003} \\
\hline & 1 & 2 & 3 & 4 & 1 & 2 & 3 & 4 & 1 & 2 & 3 & 4 & 1 & 2 & 3 & 4 & 1 & 2 & 3 & 4 \\
\hline ISOPODA & & & & & & & & & & & & & & & & & & & & \\
\hline Excirolana armata & 280 & 4 & 0 & 4 & 117 & 0 & 0 & 0 & 800 & 4 & 0 & 0 & 117 & 0 & 4 & 0 & 219 & 7 & 0 & 0 \\
\hline Macrochiridothea lilianae & 0 & 0 & 0 & 0 & 0 & 0 & 0 & 4 & 0 & 0 & 0 & 0 & 0 & 0 & 0 & 0 & 0 & 0 & 0 & 0 \\
\hline $\begin{array}{l}\text { Macrochiridothea robusta } \\
\text { AMPHIPODA }\end{array}$ & 0 & 0 & 4 & 0 & 0 & 0 & 0 & 0 & 0 & 0 & 0 & 0 & 0 & 4 & 7 & 0 & 0 & 0 & 0 & 4 \\
\hline Phoxocephalopsis sp. & 0 & 4 & 0 & 4 & 4 & 0 & 4 & 14 & 0 & 0 & 21 & 21 & 0 & 4 & 4 & 7 & 0 & 0 & 14 & 7 \\
\hline Platyischnopidae (sp. nova) & 4 & 0 & 0 & 0 & 0 & 0 & 0 & 0 & 4 & 0 & 0 & 0 & 0 & 0 & 0 & 0 & 0 & 18 & 0 & 0 \\
\hline $\begin{array}{l}\text { Puelche orensanzi } \\
\text { HIPPOIDEA }\end{array}$ & 0 & 0 & 32 & 67 & 4 & 0 & 21 & 28 & 0 & 0 & 46 & 57 & 4 & 0 & 0 & 50 & 0 & 0 & 0 & 11 \\
\hline Albunea paretii & 0 & 0 & 0 & 0 & 0 & 0 & 0 & 0 & 0 & 0 & 0 & 0 & 0 & 0 & 0 & 0 & 0 & 0 & 0 & 0 \\
\hline $\begin{array}{l}\text { Emerita brasiliensis } \\
\text { POLYCHAETA }\end{array}$ & 0 & 67 & 0 & 0 & 0 & 53 & 7 & 0 & 0 & 14 & 0 & 0 & 0 & 106 & 0 & 0 & 0 & 81 & 4 & 0 \\
\hline Euzonus furciferus & 32 & 0 & 0 & 0 & 0 & 18 & 14 & 0 & 96 & 0 & 0 & 0 & 42 & 7 & 0 & 0 & 0 & 99 & 0 & 0 \\
\hline Hemipodus olivieri & 0 & 0 & 0 & 4 & 0 & 0 & 7 & 0 & 0 & 4 & 4 & 4 & 0 & 4 & 7 & 4 & 0 & 0 & 0 & 0 \\
\hline Ophelina sp. & 0 & 0 & 0 & 0 & 0 & 0 & 0 & 0 & 0 & 0 & 0 & 0 & 0 & 0 & 0 & 0 & 0 & 4 & 7 & 0 \\
\hline Scolelepis gaucha & 0 & 0 & 0 & 0 & 0 & 11 & 0 & 0 & 0 & 4 & 0 & 0 & 0 & 18 & 0 & 0 & 0 & 53 & 0 & 0 \\
\hline $\begin{array}{l}\text { Sigalion cirriferum } \\
\text { PELECYPODA }\end{array}$ & 0 & 0 & 4 & 0 & 0 & 0 & 0 & 7 & 0 & 0 & 0 & 4 & 0 & 0 & 4 & 7 & 0 & 0 & 0 & 0 \\
\hline Donax gemmula & 0 & 4 & 4 & 46 & 7 & 0 & 11 & 46 & 0 & 4 & 18 & 32 & 0 & 0 & 0 & 53 & 0 & 0 & 0 & 21 \\
\hline Donax hanleyanus & 0 & 99 & 127 & 32 & 57 & 78 & 88 & 46 & 7 & 32 & 18 & 42 & 32 & 96 & 124 & 53 & 39 & 184 & 57 & 145 \\
\hline Mesodesma mactroides & 21 & 11 & 28 & 39 & 0 & 42 & 142 & 50 & 4 & 74 & 60 & 81 & 0 & 18 & 11 & 46 & 0 & 0 & 0 & 0 \\
\hline $\begin{array}{l}\text { Pitar rostratum } \\
\text { GASTROPODA }\end{array}$ & 0 & 0 & 0 & 0 & 0 & 0 & 0 & 0 & 0 & 0 & 0 & 0 & 0 & 0 & 0 & 0 & 0 & 0 & 0 & 0 \\
\hline Buccinanops duartei & 0 & 0 & 0 & 0 & 0 & 0 & 0 & 0 & 0 & 0 & 0 & 0 & 0 & 0 & 0 & 0 & 0 & 0 & 0 & 0 \\
\hline Heleobia sp. & 0 & 0 & 0 & 0 & 0 & 0 & 0 & 0 & 0 & 0 & 0 & 0 & 0 & 0 & 0 & 0 & 0 & 0 & 0 & 0 \\
\hline $\begin{array}{l}\text { Olivancillaria auricularia } \\
\text { ECHINOIDEA }\end{array}$ & 0 & 0 & 4 & 0 & 0 & 0 & 4 & 4 & 0 & 0 & 0 & 0 & 0 & 0 & 0 & 0 & 0 & 0 & 0 & 0 \\
\hline Mellita quinquiesperforata & 0 & 0 & 4 & 0 & 0 & 0 & 0 & 0 & 0 & 0 & 0 & 0 & 0 & 0 & 0 & 0 & 0 & 0 & 0 & 4 \\
\hline
\end{tabular}

Tabela II. Densidade média diária (ind. $/ \mathrm{m}^{2}$ ) das espécies da praia de Harmonia por estação amostral.

\begin{tabular}{|c|c|c|c|c|c|c|c|c|c|c|c|c|c|c|c|c|c|c|c|c|}
\hline & \multicolumn{4}{|c|}{07.04 .2003} & \multicolumn{4}{|c|}{08.04 .2003} & \multicolumn{4}{|c|}{09.04 .2003} & \multicolumn{4}{|c|}{10.04 .2003} & \multicolumn{4}{|c|}{11.04 .2003} \\
\hline & 1 & 2 & 3 & 4 & 1 & 2 & 3 & 4 & 1 & 2 & 3 & 4 & 1 & 2 & 3 & 4 & 1 & 2 & 3 & 4 \\
\hline ISOPODA & & & & & & & & & & & & & & & & & & & & \\
\hline Excirolana armata & 50 & 25 & 0 & 0 & 276 & 0 & 4 & 4 & 244 & 0 & 7 & 0 & 85 & 0 & 4 & 0 & 117 & 4 & 4 & 0 \\
\hline Macrochiridothea lilianae & 0 & 0 & 0 & 0 & 0 & 0 & 0 & 0 & 0 & 7 & 0 & 0 & 0 & 0 & 4 & 4 & 0 & 0 & 0 & 4 \\
\hline $\begin{array}{l}\text { Macrochiridothea robusta } \\
\text { AMPHIPODA }\end{array}$ & 0 & 0 & 0 & 4 & 0 & 0 & 4 & 0 & 0 & 0 & 4 & 0 & 0 & 0 & 0 & 0 & 0 & 0 & 0 & 0 \\
\hline Phoxocephalopsis sp. & 0 & 0 & 7 & 21 & 0 & 0 & 4 & 0 & 0 & 0 & 4 & 4 & 0 & 0 & 25 & 7 & 0 & 0 & 11 & 4 \\
\hline Platyischnopidae (sp. nova) & 0 & 0 & 0 & 0 & 0 & 0 & 0 & 0 & 0 & 0 & 0 & 0 & 0 & 0 & 4 & 0 & 0 & 4 & 0 & 4 \\
\hline $\begin{array}{l}\text { Puelche orensanzi } \\
\text { HIPPOIDEA }\end{array}$ & 0 & 4 & 4 & 25 & 0 & 0 & 18 & 35 & 4 & 39 & 71 & 32 & 0 & 0 & 32 & 32 & 0 & 0 & 0 & 25 \\
\hline Albunea paretii & 0 & 0 & 4 & 0 & 0 & 0 & 0 & 0 & 0 & 0 & 0 & 0 & 0 & 0 & 0 & 0 & 0 & 0 & 0 & 0 \\
\hline $\begin{array}{l}\text { Emerita brasiliensis } \\
\text { POLYCHAETA }\end{array}$ & 4 & 262 & 14 & 4 & 0 & 99 & 11 & 0 & 0 & 159 & 4 & 0 & 7 & 53 & 0 & 4 & 0 & 67 & 0 & 0 \\
\hline Euzonus furciferus & 0 & 11 & 4 & 0 & 7 & 0 & 0 & 0 & 14 & 0 & 0 & 0 & 39 & 0 & 0 & 0 & 18 & 39 & 0 & 0 \\
\hline Hemipodus olivieri & 0 & 4 & 25 & 0 & 0 & 0 & 11 & 11 & 0 & 0 & 7 & 11 & 0 & 7 & 4 & 14 & 0 & 0 & 4 & 11 \\
\hline Ophelina sp. & 0 & 0 & 0 & 0 & 7 & 0 & 0 & 0 & 0 & 0 & 0 & 0 & 0 & 0 & 0 & 0 & 0 & 0 & 0 & 0 \\
\hline Scolelepis gaucha & 0 & 4 & 21 & 4 & 0 & 1769 & 7 & 0 & 0 & 4 & 0 & 0 & 0 & 212 & 0 & 0 & 4 & 18 & 50 & 0 \\
\hline Sigalion cirriferum & 0 & 11 & 0 & 7 & 0 & 0 & 7 & 4 & 0 & 4 & 4 & 4 & 0 & 0 & 0 & 7 & 0 & 0 & 0 & 4 \\
\hline PELECYPODA & & & & & & & & & & & & & & & & & & & & \\
\hline Donax gemmula & 0 & 0 & 4 & 4 & 0 & 0 & 14 & 11 & 0 & 0 & 53 & 50 & 0 & 0 & 50 & 0 & 0 & 0 & 0 & 0 \\
\hline Donax hanleyanus & 0 & 42 & 42 & 39 & 0 & 7 & 110 & 21 & 7 & 35 & 21 & 0 & 0 & 67 & 60 & 7 & 7 & 180 & 60 & 67 \\
\hline Mesodesma mactroides & 0 & 0 & 0 & 11 & 14 & 32 & 88 & 21 & 4 & 53 & 88 & 173 & 4 & 14 & 336 & 67 & 0 & 11 & 32 & 42 \\
\hline $\begin{array}{l}\text { Pitar rostratum } \\
\text { GASTROPODA }\end{array}$ & 0 & 0 & 0 & 0 & 0 & 0 & 4 & 0 & 0 & 0 & 0 & 0 & 0 & 4 & 0 & 0 & 0 & 0 & 0 & 0 \\
\hline Buccinanops duartei & 0 & 0 & 0 & 0 & 0 & 0 & 0 & 0 & 0 & 0 & 0 & 4 & 0 & 0 & 0 & 0 & 0 & 0 & 0 & 0 \\
\hline Heleobia sp. & 0 & 0 & 0 & 0 & 0 & 0 & 0 & 0 & 4 & 0 & 0 & 28 & 0 & 0 & 0 & 0 & 0 & 0 & 0 & 0 \\
\hline $\begin{array}{l}\text { Olivancillaria auricularia } \\
\text { ECHINOIDEA }\end{array}$ & 0 & 0 & 0 & 0 & 0 & 0 & 0 & 0 & 0 & 0 & 0 & 0 & 0 & 0 & 0 & 4 & 0 & 0 & 0 & 0 \\
\hline Mellita quinquiesperforata & 0 & 0 & 0 & 0 & 4 & 0 & 0 & 0 & 0 & 0 & 11 & 0 & 0 & 0 & 0 & 0 & 0 & 0 & 0 & 4 \\
\hline
\end{tabular}


dominadas por M. mactroides (40\% de contribuição) e D. hanleyanus $(30 \%)$.

Nos dias 2 e 4, as estações formaram dois grupos (Fig. 7). O primeiro dominado por E. armata (75\% de contribuição), sendo formado pela estação 1 . O segundo grupo reuniu as estações 2, 3 e 4 e caracterizou-se pelas presenças de D. hanleyanus e $M$. mactroides (contribuição > 80\%).

Nos dias 3 e 5, as estações formaram três grupos (Fig. 7). O primeiro incluiu somente a estação 1 e foi dominado por E. armata ( $90 \%$ de contribuição) e $E$. furciferus ( $20 \%$ de contribuição) no terceiro dia, enquanto somente E. armata (99\% de contribuição) dominou o quinto dia. O segundo grupo foi formado pela estação 2 e apresentou dominância, no dia 3 , de D. hanleyanus (90\% de contribuição). No dia 5, neste grupo predominaram, além de D. hanleyanus $(34 \%$ de contribuição), S. gaucha (23\% de contribuição) e $E$. armata (20\% de contribuição). A estação 4 formou o terceiro grupo, com dominância de D. gemmula (58\% de contribuição) e D. hanleyanus (33\% de contribuição) no dia 3 e somente $D$. hanleyanus (93\% de contribuição) no quinto dia.

As espécies Sigalion cirriferum e Buccinanops duartei, apesar de pouco abundantes, foram características da zona de arrebentação interna (Tab. III).

As três praias. O caranguejo Ocypode quadrata (Fabricius, 1787) foi encontrado no supralitoral das três praias estudadas com densidades variáveis. Estes resultados foram publicados por NEVES \& BEMVENUTI (2006). Neste trabalho, uma nova espécie de Amphipoda da família Platyischnopidae foi identificada pela Dra. Cristiana Serejo Young, do Museu Nacional do Rio de Janeiro.

Não foram encontradas diferenças significativas na abundância e composição da comunidade bentônica nas estações de coleta entre transversais dentro de uma mesma praia (ANOSIM; p>0,05). Estas estações foram comparadas uma a uma dentro de cada praia. Além disso, também não foi verificada diferença das transversais entre as três praias (ANOSIM; $\mathrm{p}>0,05$ ).

Analisando os dados das três praias em conjunto, observou-se o mesmo padrão já descrito para cada uma individualmente. As estações foram separadas em três grupos (Fig. 8, Tab. IV), sendo o primeiro formado pela estação 1 , o segundo pela estação 2 e o terceiro pelas estações 3 e 4.

O grupo 1 foi dominado por E. armata, o grupo 2 foi composto principalmente por $E$. brasiliensis, $S$. gaucha e baixa representatividade de D. gemmula e o grupo 3 dominado por $D$. hanleyanus e, em menor grau, por M. mactroides.

Analisando a variação da zonação a cada dia, observou-se nos dois primeiros dias a separação de dois

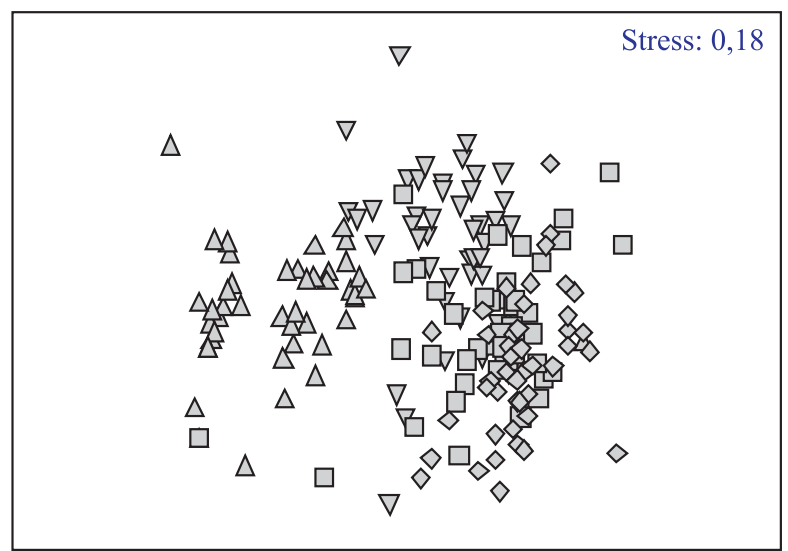

Fig. 8. Análise de ordenação MDS da distribuição vertical das amostras das três praias estudadas ao longo dos cinco dias de amostragem (abril de 2003) ( $\boldsymbol{\Lambda}$, estação $1 ; \boldsymbol{\nabla}$, estação $2 ; \boldsymbol{\nabla}$, estação $3 ; \boldsymbol{\square}$, estação 4).

Tabela III. Densidade média diária (ind. $/ \mathrm{m}^{2}$ ) das espécies da praia de Jardim do Éden por estação amostral.

\begin{tabular}{|c|c|c|c|c|c|c|c|c|c|c|c|c|c|c|c|c|c|c|c|c|}
\hline & \multicolumn{4}{|c|}{07.04 .2003} & \multicolumn{4}{|c|}{08.04 .2003} & \multicolumn{4}{|c|}{09.04 .2003} & \multicolumn{4}{|c|}{10.04 .2003} & \multicolumn{4}{|c|}{11.04 .2003} \\
\hline & 1 & 2 & 3 & 4 & 1 & 2 & 3 & 4 & 1 & 2 & 3 & 4 & 1 & 2 & 3 & 4 & 1 & 2 & 3 & 4 \\
\hline ISOPODA & & & & & & & & & & & & & & & & & & & & \\
\hline Excirolana armata & 807 & 124 & 0 & 0 & 1040 & 7 & 11 & 4 & 471 & 0 & 0 & 0 & 1037 & 4 & 4 & 0 & 1122 & 152 & 11 & 0 \\
\hline Macrochiridothea lilianae & 0 & 0 & 0 & 0 & 0 & 0 & 4 & 4 & 4 & 7 & 4 & 4 & 0 & 7 & 7 & 0 & 0 & 4 & 0 & 0 \\
\hline $\begin{array}{l}\text { Macrochiridothea robusta } \\
\text { AMPHIPODA }\end{array}$ & 0 & 0 & 0 & 0 & 0 & 0 & 0 & 0 & 0 & 0 & 0 & 0 & 0 & 0 & 0 & 0 & 0 & 0 & 0 & 0 \\
\hline Phoxocephalopsis sp. & 0 & 21 & 18 & 4 & 0 & 25 & 21 & 18 & 4 & 7 & 11 & 21 & 0 & 7 & 25 & 11 & 0 & 0 & 18 & 25 \\
\hline Platyischnopidae (sp. nova) & 96 & 11 & 0 & 0 & 85 & 7 & 7 & 0 & 152 & 0 & 11 & 0 & 0 & 0 & 0 & 0 & 14 & 134 & 32 & 0 \\
\hline $\begin{array}{l}\text { Puelche orensanzi } \\
\text { HIPPOIDEA }\end{array}$ & 0 & 0 & 28 & 14 & 0 & 4 & 14 & 4 & 0 & 4 & 21 & 32 & 7 & 0 & 14 & 7 & 0 & 0 & 0 & 0 \\
\hline Albunea paretii & 0 & 0 & 0 & 0 & 0 & 0 & 0 & 0 & 0 & 0 & 0 & 0 & 0 & 0 & 0 & 4 & 0 & 0 & 0 & 0 \\
\hline $\begin{array}{l}\text { Emerita brasiliensis } \\
\text { POLYCHAETA }\end{array}$ & 4 & 57 & 0 & 0 & 0 & 11 & 14 & 7 & 0 & 28 & 0 & 0 & 0 & 14 & 0 & 0 & 0 & 71 & 0 & 0 \\
\hline Euzonus furciferus & 4 & 0 & 0 & 0 & 198 & 0 & 4 & 0 & 21 & 0 & 0 & 0 & 340 & 0 & 0 & 0 & 4 & 18 & 18 & 0 \\
\hline Hemipodus olivieri & 0 & 0 & 7 & 0 & 0 & 4 & 7 & 7 & 0 & 14 & 7 & 25 & 0 & 7 & 14 & 4 & 0 & 0 & 11 & 0 \\
\hline Ophelina sp. & 0 & 0 & 0 & 0 & 0 & 0 & & 0 & 0 & 0 & 0 & 0 & 0 & 0 & 0 & 0 & 0 & 7 & 11 & 0 \\
\hline Scolelepis gaucha & 0 & 117 & 0 & 0 & 0 & 14 & 18 & 0 & 283 & 7 & 0 & 0 & 110 & 0 & 0 & 0 & 4 & 202 & 57 & 0 \\
\hline $\begin{array}{l}\text { Sigalion cirriferum } \\
\text { PELECYPODA }\end{array}$ & 0 & 0 & 0 & 7 & 0 & 0 & 4 & 4 & 0 & 7 & 7 & 11 & 0 & 0 & 14 & 4 & 0 & 0 & 7 & 4 \\
\hline Donax gemmula & 0 & 0 & 0 & 18 & 0 & 4 & 7 & 11 & 0 & 7 & 18 & 81 & 0 & 7 & 11 & 74 & 0 & 0 & 0 & 21 \\
\hline Donax hanleyanus & 11 & 814 & 198 & 106 & 311 & 198 & 308 & 283 & 322 & 92 & 60 & 14 & 7 & 407 & 138 & 166 & 14 & 318 & 159 & 276 \\
\hline Mesodesma mactroides & 272 & 42 & 78 & 188 & 25 & 127 & 85 & 255 & 4 & 25 & 92 & 347 & 0 & 18 & 14 & 71 & 0 & 0 & 0 & 4 \\
\hline $\begin{array}{l}\text { Pitar rostratum } \\
\text { GASTROPODA }\end{array}$ & 0 & 0 & 0 & 0 & 0 & 0 & 0 & 0 & 0 & 0 & 0 & 0 & 0 & 0 & 0 & 0 & 0 & 0 & 0 & 0 \\
\hline Buccinanops duartei & 0 & 0 & 4 & 0 & 0 & 0 & 4 & 0 & 0 & 0 & 0 & 0 & 0 & 0 & 4 & 4 & 0 & 0 & 0 & 7 \\
\hline Heleobia sp. & 0 & 0 & 0 & 0 & 0 & 0 & 0 & 0 & 0 & 0 & 0 & 0 & 0 & 0 & 0 & 0 & 0 & 0 & 0 & 0 \\
\hline $\begin{array}{l}\text { Olivancillaria auricularia } \\
\text { ECHINOIDEA }\end{array}$ & 0 & 0 & 0 & 0 & 0 & 0 & 0 & 0 & 0 & 0 & 0 & 0 & 0 & 0 & 0 & 0 & 0 & 0 & 4 & 0 \\
\hline Mellita quinquiesperforata & 0 & 0 & 4 & 0 & 0 & 0 & 0 & 0 & 0 & 0 & 0 & 11 & 0 & 0 & 7 & 4 & 0 & 0 & 0 & 0 \\
\hline
\end{tabular}


Tabela IV. Análise de similaridade (ANOSIM) com os dados das três praias. Foram utilizadas as estações como fatores (R estatístico global $=0,515 ; \mathrm{p}=0,1 \%)$.

\begin{tabular}{ccc}
\hline Estações & R estatístico & $P(\%)$ \\
\hline $1-2$ & 0,708 & 0,1 \\
$1-3$ & 0,743 & 0,1 \\
$1-4$ & 0,835 & 0,1 \\
$2-3$ & 0,278 & 0,1 \\
$2-4$ & 0,428 & 0,1 \\
$3-4$ & 0,032 & 1,3 \\
\hline
\end{tabular}

grupos, como no padrão geral, um grupo formado pela estação 1 e outro formado pelas estações 2,3 e 4 . A estação 1 apresentou dominância em ambos os dias de $E$. armata (contribuição > 80\%), porém, no segundo dia, $D$. hanleyanus ( $10 \%$ de contribuição) também apareceu neste nível da praia. No segundo grupo, $D$. hanleyanus e M. mactroides dominaram nos dois primeiros dias (contribuição > 70\%), além de P. orensanzi $(10 \%$ de contribuição) e E. brasiliensis (5\% de contribuição).

Nos outros três dias a separação das estações seguiu um padrão com três grupos, sendo um grupo formado pela estação 1, um segundo grupo formado pela estação 2 e um terceiro formado pela estação 4 . A estação 3 foi intermediária, apresentando espécies das outras estações. Nestes três dias, a estação 1 foi dominada por E. armata (contribuição > 60\%), além de E. furciferus (37\% de contribuição) no dia 4 .

No dia 3, as diferenças entre as estações 2 e 4 foram devidas principalmente à presença de M. mactroides (33\% na dissimilaridade entre estações) na estação 4 e $E$. brasiliensis (13\%) na estação 2. Porém estas duas estações apresentaram dominância de $M$. mactroides ( $40 \%$ contribuição na similaridade da estação).

As espécies $D$. hanleyanus ( $31 \%$ dissimilaridade), S. gaucha (13\%), E. brasiliensis (12\%) e M. mactroides (13\%) foram as principais responsáveis pelas diferenças entre as estações 2 e 4 no quarto dia. As três primeiras espécies pertenciam à estação 2 , enquanto a última pertencia à estação 4.

No quinto dia, a estação 2 se diferenciou das estações 3 e 4 pela presença das espécies $D$. hanleyanus (32\% na dissimilaridade), S. gaucha (17\%), E. brasiliensis (15\%) e E. furciferus (11\%) em maiores abundâncias na estação 2 .

\section{DISCUSSÃO}

Relação da macrofauna com o ambiente. Os resultados mostram que ocorreram dois fenômenos de maré meteorológica (ressaca) durante este estudo. Os dados de velocidade do vento e distância das dunas até a zona de varrido foram os indicadores dos processos de subida e descida da linha d'água causados pelos fenômenos de ressaca, que ocorreram no início e no final do período de amostragem. Estes fenômenos elevaram o limite superior do mesolitoral, podendo ser o principal fator que explica a variação diária da estrutura da macrofauna das praias estudadas. Na praia de Harmonia, por exemplo, o limite superior da zona de varrido chegou a $27 \mathrm{~m}$ das dunas no primeiro dia, recuando para $35 \mathrm{~m}$ no terceiro dia e voltando a subir para $29 \mathrm{~m}$ das dunas no último dia de amostragem.

GianUCA (1983) ressalta que as tempestades costeiras são eventos comuns no litoral do Rio Grande do Sul, estando associadas a ventos do quadrante sul, os quais produzem um aumento da turbulência na região infralitoral superior. Nestas condições, o nível do mar pode alcançar alturas de cerca de $2 \mathrm{~m}$ (BARLETTA \& CALLIARI, 2003), chegando até mesmo no supralitoral.

Estes fenômenos meteorológicos foram confirmados com a observação de manchas amarronzadas da diatomácea Asterionellopsis glacialis, desde a zona de arrebentação até a zona de varrido nas três praias. Altas concentrações desta espécie bentônica são ressuspendidas e acumuladas na zona de arrebentação durante passagens cíclicas de frentes frias, com fortes ventos do quadrante sul (GianucA, 1983; ODEBRECht et al., 1995, 2003).

Além disso, a presença do gastrópode Olivancillaria auricularia e de Mellita quinquiesperforata na zona de varrido sugerem uma maior hidrodinâmica nas praias. Como este estudo iniciou-se no final de uma ressaca, os reflexos deste fenômeno foram notados no início do período amostral, sendo observada uma alta abundância de M. quinquiesperforata nas praias de Harmonia e Jardim do Éden. Este organismo é um comedor de depósitos e suspensívoro (Findlay \& White, 1983) típico do infralitoral (GiAnUCA, 1983) e sua presença na zona de varrido é somente percebida associada a fenômenos de ressaca ou empilhamento de água na costa. No que concerne a $O$. auricularia, esta espécie migra ativamente até a zona de varrido utilizando a energia das ondas (ROCHA-BARREIRA, 2002) para predar, principalmente, Emerita brasiliensis, Mesodesma mactroides e Donax hanleyanus (Gianuca, 1983). Neste trabalho, $O$. auricularia pode ter tido um incremento na sua presença na zona de varrido devido à maior energia de onda proporcionada pela ressaca. No entanto, não se conhece a abundância desta espécie em outras situações nas praias estudadas.

O tamanho do grão de sedimento não apresentou diferença entre as estações de coleta dentro de cada praia, tampouco entre praias, variando de $0,19 \mathrm{~mm}$ até $0,25 \mathrm{~mm}$. Esta composição de areia fina é característica de praias intermediárias, juntamente com ondas de alturas moderadas a altas ( 0,5 a 2,5 m) e períodos longos (SHORT, 2003). Alguns estudos mostram que a riqueza de espécies, densidade e biomassa da macrofauna são inversamente relacionadas ao tamanho do grão de sedimento e declividade da praia (MClaChlan et al., 1993; Defeo et al., 1992). Os resultados do presente trabalho mostram que a granulometria do sedimento não foi um fator que determinou uma variação na estrutura da macrofauna nas três praias.

Os perfis topográficos das praias apresentaram pouca variação ao longo dos dias. Somente no último dia, em Harmonia, verificou-se um processo de erosão na praia. Este processo possivelmente foi causado pela maré meteorológica que ocorreu neste dia e apresentou ondas de menor altura com período curto.

Os resultados evidenciam que o principal fator ambiental diretamente responsável pela alteração da 
distribuição vertical da macrofauna nas praias estudadas foi a variação dos limites da zona de varrido causada pelas ressacas. É importante ressaltar que as marés meteorológicas também carregaram organismos típicos do infralitoral para a zona de varrido, alterando temporariamente a composição de espécies.

Variabilidade diária da macrofauna bentônica. As zonas mais altas das praias foram as mais estáveis temporalmente. Excluindo-se o supralitoral, no qual foram somente quantificadas as densidades das tocas do $O$. quadrata, o mesolitoral superior foi a região mais estável ao longo deste estudo.

Excirolana armata esteve presente nesta região em maiores densidades todos os dias, juntamente com Euzonus furciferus em alguns dias. Esta região pode ser comparada à "faixa de cirolanídeos" proposta por DAHL (1952). No entanto, alguns autores (BRASEIRO \& DEFEO, 1996) não encontraram esta faixa de cirolanídeos tão marcada em praias temperadas da América do Sul. Ao invés disso, observaram uma ampla distribuição de $E$. armata, além da presença de E. brasiliensis no supralitoral. BRAZEIRO \& DEFEO (1996), em um estudo de um ano na costa do Uruguai, encontraram um comportamento dinâmico diferente para E. armata. Esta espécie ocupou as zonas mais altas de sua distribuição durante o outono e primavera (acima do nível médio da água) e habitou níveis mais baixos durante o inverno (abaixo do nível médio da água).

A região do mesolitoral inferior e arrebentação interna foi a mais instável nas três praias. Esta é a região que está mais sujeita à ação de subida e descida da água, além da ação direta das ondas nas zonas mais baixas (estação 4) e a influência de correntes de deriva. Em sua porção superior (varrido), encontraram-se os migradores mareais em maior abundância, como E. brasilienses, $D$. hanleyanus e M. mactroides, além de S. gaucha. Estas espécies também foram encontradas na região inferior desta zona, porém em menor abundância. BRAZEIRO \& DEFEO (1996) também encontraram resultados semelhantes para essa região.

Um importante componente da comunidade bentônica de praias arenosas do Rio Grande do Sul é o poliqueta $S$. gaucha, o qual se distribui desde o norte deste Estado até o Uruguai (ORENSANZ \& GianUCA, 1974). Esta espécie é típica do mesolitoral, apresentando grande flutuação em sua densidade (SANTOS, 1991). Os resultados do presente trabalho mostram que $S$. gaucha apresentou considerável variação em sua densidade no período amostral, principalmente na praia de Harmonia, onde a densidade na estação 2 variou de $4 \mathrm{ind} / \mathrm{m}^{2}$ até cerca de $1700 \mathrm{ind} / \mathrm{m}^{2}$.

O presente trabalho sugere que o padrão de zonação de praias arenosas intermediárias e dissipativas não é estático, ou seja, a macrofauna ajusta sua posição na praia de acordo com suas necessidades momentâneas perante eventos ambientais comuns nesta região (marés meteorológicas, erosão da praia). MCLACHLAN \& JARAMILLO (1995) enfatizaram que não existe relação entre as zonas faunísticas da praia e níveis de maré de médio ou de longo prazo. Dessa forma, as zonas se ajustam a cada dia aos limites da praia, definidos pela variação da zona de varrido. RAFFAELLI et al. (1991) consideram que, excetuando-se as zonas mais altas da praia, torna-se difícil definir as zonas biológicas em praias arenosas.

Praia de Tramandaí. Na praia de Tramandaí não ocorreu variação dos limites verticais da zona de varrido tão marcada como nas praias de Harmonia e Jardim do Éden. A plataforma de pesca de Tramandaí, a qual se localiza a cerca de $200 \mathrm{~m}$ da região onde foram feitos os perfis amostrais deste trabalho pode ser um fator importante na hidrodinâmica litorânea do seu entorno, minimizando o impacto de ondas na costa e tornando esta região da praia mais dissipativa. Além disto, observase com frequência correntes de retorno próximas a esta plataforma.

Pode-se verificar que a praia de Tramandaí apresentou uma zona de varrido e de arrebentação mais extensa que as outras duas praias. Este fato é confirmado pela maior distância da estação 4 (localizada sempre na profundidade de $1 \mathrm{~m}$ ) em relação à estação 1 , e a menor declividade desta praia $\left(1,3^{\circ}\right)$ em relação a Harmonia e Jardim do Éden.

A pequena variação dos limites da zona de varrido pode explicar a menor variação da posição vertical da macrofauna nesta praia nos dias estudados.

Como nas outras praias, E. armata foi a espécie característica do mesolitoral superior, juntamente com o poliqueta E. furciferus em alguns dias. Resultados semelhantes foram encontrados por GIANUCA (1983) para praias do litoral sul do Rio Grande do Sul. O migrador mareal E. brasiliensis esteve presente todos os dias em maior abundância na estação 2 , enquanto o pelecípode migrador mareal $D$. hanleyanus apresentou uma ampla distribuição no mesolitoral desta praia. Estes resultados estão de acordo com os padrões de zonação propostos por GiANUCA (1983) e BRAZEIRO \& DeFEO (1996).

Um fato marcante nos resultados desta praia foi o desaparecimento dos juvenis do migrador mareal $M$. mactroides no último dia amostral em todas as estações. Os juvenis desta espécie apresentam capacidade restrita de enterramento, ficando numa faixa de profundidade na casa de milímetros, ao passo que os adultos (cerca de 7 $\mathrm{cm}$ de comprimento) podem se enterrar até cerca de 40 $\mathrm{cm}$, dependendo da compactação do sedimento (OLIVIER \& Penchaszadeh, 1968). Essa espécie provavelmente desapareceu das amostras devido à maior hidrodinâmica no último dia causada pela ressaca, sendo os organismos facilmente retirados do sedimento e carreados para outras regiões da praia em função de correntes de deriva.

Praia de Harmonia. Tal como a praia de Jardim do Éden, essa praia apresentou grande variação vertical dos limites da zona de varrido ao longo do estudo, principalmente devido aos fenômenos de ressaca que ocorreram no início e final deste estudo.

Algumas espécies apresentaram distribuição vertical numa faixa delimitada da praia, apesar da variação dos limites da zona de varrido. O poliqueta $E$ furciferus foi encontrado nas estações intermediárias (estações 2 e 3) nos dias 1 e 5, sendo estes dias marcados pela subida dos limites da zona de varrido. No entanto, nos dias 2, 3 e 4, como os limites da zona de varrido desceram, esta espécie ocorreu somente na estação mais alta. Estes resultados mostram que o poliqueta E. furciferus apresentou uma faixa delimitada de distribuição na praia 
durante este estudo, no entanto, as estações de coleta tiveram as posições alteradas em virtude da variação dos limites da zona de varrido. Euzonus furciferus é uma espécie típica do mesolitoral (SoUZA \& GiANUCA, 1995), apresentando distribuição em manchas e pouca movimentação na praia, principalmente em função da seleção passiva pelas ondas e da concentração de alimento localizada (MCLACHLAN \& HesP, 1984). Provavelmente, somente eventos mais longos de subida e descida do nível do mar poderiam afetar a posição vertical de $E$. furciferus na praia.

Os migradores mareais $D$. hanleyanus e $M$. mactroides apresentaram ampla distribuição no mesolitoral. Estes organismos foram em sua maioria juvenis. Outro migrador mareal, E. brasiliensis, apresentou suas maiores densidades na estação 2 em todos os dias, concordando com os resultados de GIANUCA (1983). Os anfípodes Phoxocephalopsis sp. e P. orensanzi foram encontrados todos os dias em maiores abundâncias nas estações inferiores da praia. Porém, $P$. orensanzi também ocorreu em estações mais altas da praia em menores densidades.

Praia de Jardim do Éden. Essa praia apresentou a maior densidade de E. armata na estação 1 em todos os dias em relação às outras estações. Observa-se, no entanto, que a densidade desta espécie também foi alta na estação 2 nos dias 1 e 5 . Tais dias foram marcados pelas marés meteorológicas, as quais fizeram com que o nível do mar subisse e, conseqüentemente, também os limites da zona de varrido. Este fato pode explicar as altas densidades de E. armata na estação 2 (além da estação 1) já que estas estações passaram a ocupar níveis mais altos na praia e possivelmente foram localizadas sobre a faixa de E. armata nos dias 1 e 5 . Este resultado mostra que E. armata apresentou distribuição vertical numa faixa delimitada da praia, sendo a posição das estações alterada devido à variação dos limites da zona de varrido (a estação 1 foi sempre localizada $8 \mathrm{~m}$ acima do limite superior da zona de varrido no momento da coleta). As variações no nível da maré devem ser consideradas descritores importantes do gradiente faunístico do mesolitoral, sendo um fator chave na forma e intensidade da distribuição em manchas e na posição da fauna nos níveis da praia (BRAZEIRO \& DEFEO, 1996).

Além de $E$. armata, outras espécies também tiveram posição vertical numa faixa delimitada da praia, apesar da variação dos limites da zona de varrido. O bivalve $D$. gemmula, o poliqueta $H$. olivieri e o anfípode $P$. orensanzi apareceram nas zonas mais baixas da praia nos dias 1 e 5 . No entanto, nos dias 2, 3 e 4 estas espécies se distribuíram por uma faixa mais ampla, chegando a ocupar até a estação 1 , como foi o caso de $P$. orensanzi no dia 4. A ocorrência destas espécies nas estações 1 e 2 nos dias entre ressacas foi influenciada pela descida das estações de coleta que acompanharam o recuo do nível do mar. Assim, foram as estações de coleta que desceram junto com os limites da zona de varrido e se localizaram nas regiões mais baixas, ao passo que as espécies permaneceram na mesma faixa da praia. De acordo com Gianuca (1985), D. gemmula é a espécie mais abundante da zona de arrebentação interna em praias do litoral sul do Rio Grande do Sul.
Juvenis dos migradores mareais $D$. hanleyanus e M. mactroides apresentaram uma ampla distribuição vertical na praia ao longo do estudo, ocorrendo desde a estação 1 até a estação 4. A incidência diferencial de fatores ambientais (e.g., distúrbio por ondas, temperatura, dessecação) sobre cada espécie e componentes da população (e.g., recrutas, adultos), pode determinar uma distribuição distinta da macroinfauna em praias arenosas (BRASEIRO \& DEFEO, 1996). Enquanto organismos menores são mais dependentes de transporte passivo, a variabilidade sazonal nos padrões de zonação de adultos e espécies de tamanho maior pode ser considerada o resultado de um processo ativo que envolve certo nível de mobilidade e um complexo conjunto de adaptações à variabilidade ambiental (Defeo \& Mclachlan, 2005).

O hipídeo migrador mareal Emerita brasiliensis foi uma espécie típica da zona de varrido durante este estudo. Esta espécie necessita se locomover constantemente nesta região da praia para se alimentar de material em suspensão na água, principalmente espécies fitoplanctônicas (GIANUCA, 1983).

O poliqueta $S$. cirriferum, o isópode $M$. lilianae e o gastrópode Buccinanops duartei foram espécies típicas das zonas de mesolitoral inferior e arrebentação interna, com pouca variação em suas posições na praia ao longo dos dias. Estes resultados estão de acordo com os resultados encontrados por GIANUCA (1983) para as praias do litoral do Rio Grande do Sul.

\section{CONCLUSÕES}

Os resultados deste trabalho mostram que as praias de Tramandaí, Harmonia e Jardim do Éden apresentaram um padrão de zonação da macrofauna bentônica típico de praias arenosas de acordo com o esquema biológico proposto por DAHL (1952) e o esquema físico proposto por SALVAT (1964). No entanto, a zona de saturação e arrebentação interna apresentaram alta similaridade.

Nas praias estudadas, as zonas mais altas apresentaram maior estabilidade temporal da fauna do que as zonas mais baixas (mesolitoral inferior e zona de arrebentação interna).

Essas praias apresentaram variação ambiental relativamente pequena, principalmente considerando a granulometria do sedimento e a declividade dos perfis topográficos. Neste sentido, um fator chave para se entender a variação diária da macrofauna encontrada neste trabalho, foi a variação dos limites da zona de varrido causada pelos fenômenos de ressaca que ocorreram no início e no final do período amostral.

Agradecimentos. Os autores agradecem ao técnico Nilton Araújo pelo auxílio na triagem e identificação dos organismos, aos pós-graduandos Leonir A. Colling e Pedro Pereira pelo auxílio nos trabalhos de campo, a Dra. Cristiana S. Young (MNRJ) pela identificação dos espécimes de Amphipoda e à Dra. Norma Würdig pela revisão do manuscrito. FMN agradece ao Conselho Nacional de Pesquisa (CNPq) pela bolsa de estudos.

\section{REFERÊNCIAS BIBLIOGRÁFICAS}

Barletta, R. C. \& Calliari, L. J. 2003. An assessment of the atmospheric and wave aspects determining beach morphodynamic characteristics along the central coast of RS 
state, southern Brazil. Journal of Coastal Research (Special Issue) 35:300-308

BiRKEMEIER, W. A. 1985. Fast, accurate two person beach surveys. Coastal Engineering Technical Aid 81:1-17.

Borzone, C. A. \& Gianuca, N. M. 1990. A zonação infralitoral em praias arenosas expostas. In: $2^{\circ}$ Simpósio SOBRE Ecossistemas DA Costa Sul e Sudeste Brasileira. Anais... São Paulo, Publ. ACIESP 3:280-296.

Borzone, C. A. \& SouzA, J. R. B. 1997. Estrutura da macrofauna bentônica no supra, meso e infralitoral de uma praia arenosa do sul do Brasil. Oecologia Brasiliensis 3:197-212.

Borzone, C. A.; Souza, J. R. B. \& Soares, A. G. 1996. Morphodynamic influence on the structure of inter and subtidal macrofaunal communities of subtropical sandy beaches. Revista Chilena Historia Natural 69:565-577.

Brazeiro, A. \& Defeo, O. 1996. Macroinfauna zonation in macrotidal sandy beaches: is it possible to identify patterns in such variable environments? Estuarine, Coastal and Shelf Science 42:523-536.

Brown, A. C. \& Mclachlan, A. 1990. Ecology of sandy shores. Amsterdam, Elsevier. 387p.

DAHL, E. 1952. Some aspects of the ecology and zonation of the fauna of sandy beaches. Oikos 4:1-27.

Defeo, O.; Jaramillo, A. \& Lyonnet, A. 1992. Community structure and intertidal zonation of the macroinfauna on the Atlantic coasts of Uruguay. Journal of Coastal Research 8:830-839.

Defeo, O. \& Mclachlan, O. 2005. Patterns, processes and regulatory mechanisms in sandy beach macrofauna: a multiscale analysis. Marine Ecology Progress Series 295:1-20.

Findlay, R. H. \& White, D. C. 1983. The effects of feeding by the sand dollar Mellita quinquiesperforata (Leske) on the benthic microbial community. Journal of Experimental Marine Biology and Ecology 72:25-41.

Gianuca, N. M. 1983. A preliminary account of the ecology of sandy beaches in southern Brazil. In: McLachlan, A. \& ERASMUS, T. eds. Sandy beaches as ecosystems. The Hague, Junk. p. 413-420.

Jaramillo, E.; Mclachlan, A \& Coetzee, P. 1993. Intertidal zonation patterns of macroinfauna over a range of exposed sandy beaches in south-central Chile. Marine Ecology Progress Series 101:105-118.

Leber, K. M. 1982. Seasonality of macroinvertebrates on a temperate, high wave, energy sandy beach. Bulletin of Marine Science 32:86-98.

McLachlan, A. 1983. Sandy beaches ecology - a review. In: Mclachlan, A. \& Erasmus, T. eds. Sandy Beaches as Ecosystems. The Hague, Junk. p.321-380. 1990. Dissipative beaches and macrofaunal communities on exposed intertidal sands. Journal of Coastal Reserch 6:57-71. . 1996. Phisical factors in benthic ecology: effects of changing sand particle size on beach fauna. Marine Ecology Progress Series 131:205-211.

McLachlan, A. \& Hesp, P. 1984. Faunal response to morphology and water circulation of a sandy beach with cusps. Marine Ecology Progress Series 19:133-144.

McLachlan, A. \& Jaramillo, E. 1995. Zonation on sandy beaches. Oceanography and Marine Biology. Annual Review 33:305-335.

Mclachlan, A.; Jaramillo, E.; Donn, T. E. \& Wessels, E. 1993. Sandy beach macrofauna communities and their control by the physical environment: a geographical comparison Journal of Coastal Reserch (Special Issue) 15:27-38.

Neves, F. M. \& Bemvenuti, C. E. 2006. The ghost crab Ocypode quadrata (Fabricius, 1787) as a potential indicator of anthropic impact along the Rio Grande do Sul coast, Brazil. Biological Conservation 133:431-435.

Odebrecht, C; Abreu, P. C.; Fugita, C. C. \& Bergesch, M. 2003. The impact of mud deposition on the long term variability of the surf-zone diatom Asterionellopsis glacialis (Castracane) round at Cassino beach, Brazil. Journal of Coastal Research (Special Issue) 35:486-491.

Odebrecht, C.; Segatto, A. Z. \& Freitas, C. A. 1995. Surf-zone chlorophyll a variability at Cassino beach, southern Brazil Estuarine, Coastal and Shelf Science 41:81-90.

Olivier, S. R. \& Penchaszdeh, P. E. 1968. Evaluacion de los efectivos de almeja amarilla (Mesodesma mactroides DESH, 1854) en las costas de la provincia de Buenos Aires. Serie Informes Técnicos (Proyeto de desarrollo pesquero Gobierno Argentino), PDT, Mar del Plata, 6p.

Orensanz, J. M. \& Gianuca, N. M. 1974. Contribuição ao conhecimento dos anelídeos poliquetas do Rio Grande do Sul. I. Lista sistemática preliminar e descrição de três novas espécies. Comunicações do Museu de Ciências PUCRS 4:1-37.

Raffaelli, D. G.; Karakassis, I. \& Galloway, A. 1991. Zonation schemes on sandy shores: a multivariate approach. Journal of Experimental Marine Biology and Ecology 148:241253.

Rocha-BARReIRA, C. A. 2002. Feeding Behavior of Olivancillaria vesica auricularia (Lamarck, 1810): (Mollusca, Olividae). Thalassas 18(2):83-89.

Salvat, B. 1964. Les conditions hydrodinamicques interstitielles des sedimentes meubles intertidaus et la repartition verticale de la faune endogée. Chiers Recherche Academic Scientific 259:1576-1579.

SANTOS, P. J. P. 1991. Morphodynamical influence of a temporary freshwater stream on the population dynamics of Scolelepis gaucha (Polychaeta: Spionidae) on a sandy beach in southern Brazil. Bulletin of Marine Science 48(3):657-664.

Schwarzbold, A \& Wurdig, N. L. 1992. Lagoas costeiras do Rio Grande do Sul. In: Diagnóstico Ambiental Oceânico e Costeiro das Regiões Sul e Sudeste do Brasil. Rio de Janeiro, PETROBRAS. v.1. p.94-97.

Short, A. D. 2003. Australian beach systems - The morphodynamics of wave through tide-dominated beachdune systems. Journal of Coastal Reserch (Special Issue) 35:7-20.

SouZA, J. R. B. \& GianucA, N. M. 1995. Zonation and seasonal variation of the intertidal macrofauna on a sandy beach of Paraná State, Brazil. Scientia Marina 59(2):103-111.

TARR, J. G.; GRIFFIths, C. L. \& BALly, R. 1985. The ecology of three sandy beaches on the Skeleton Coast of South West Africa. Madoqua 14:293-304.

Villwock, J. A. 1994. A costa brasileira: Geologia e Evolução. Anais In: $3^{\circ}$ Simpósio de Ecossistemas da Costa Brasileira Subsídios a um Gerenciamento Ambiental. Anais... São Paulo, Publ. ACIESP 3(87):1-15.

Wright, L. D. \& SHORT, A. D. 1984. Morphodynamic variability of surf zones and beaches: a synthesis. Marine Geology 48:259-284. 